\title{
Las tretas del débil: la autotraducción como subversión lingüística patriarcal en la literatura de la escritora puertorriqueña Rosario Ferrél
}

\author{
Aurora Sambolín-Santiago \\ asambolin@uct.cl \\ Universidad Católica de Temuco, Chile
}

\begin{abstract}
Resumen
La subversión lingüística ha sido una herramienta rupturista para muchas escritoras y escritores en toda Latinoamérica en diferentes momentos de su historia, frente al canon literario y la homogenización de las diferentes identidades nacionales. En este contexto se analiza la literatura de Rosario Ferré, quien forma parte de la Generación del 70 puertorriqueña que impulsó conceptualizaciones sobre identidades puertorriqueñas híbridas. Estas conceptualizaciones transgredieron la identidad nacional hispanófila que algunas instituciones y organizaciones políticas isleñas habían oficializado en contraposición a los intentos colonialistas de los Estados Unidos por asimilar lingüística y culturalmente a los/las puertorriqueñas. Dentro de este contexto, el caso de la escritora Rosario Ferré es muy especial debido a su posición político-social, su particular incursión en el mercado literario estadounidense, al publicar en un inglés "contaminado" lingüística y culturalmente por el español, y su práctica subversiva de autotraducción sobre la que elegantemente se da el lujo de teorizar en una de las tramas de su novela The House on the Lagoon (1995), que se examina en este artículo.
\end{abstract}

Palabras clave: autotraducción, hibridez lingüística, literatura poscolonial, literatura puertorriqueña, estudios de traducción

\section{Ruses of the weak: Self-translation as linguistic and patriarchal subversion in Puerto Rican writer Rosario Ferré's writing}

\begin{abstract}
Linguistic subversion has been a paradigm-breaking tool for many writers to rise against the literary canon and the homogenization of national identities all over Latin America at different times in history. In this context, Rosario Ferré's writing is analyzed. Ferré grew up as a member of the Puerto Rican 70's Generation, which drove conceptualizations about Puerto Rican hybrid identities. These conceptualizations called into question a Hispanophile national identity that some of the island's institutions and political organizations had made official, in opposition against the US colonialist attempts to linguistically and culturally assimilate Puerto Rican people. In this literary setting, Rosario Ferrés case stands out due to her sociopolitical position, her particular incursion into the US literary market with English written publications linguistically and culturally "contami-
\end{abstract}

1 La investigación que sustenta este artículo se desarrolló en el marco de la tesis doctoral de la autora, titulada The Phenomenon of Self-Translation in Puerto Rican and Puerto Rican U.S. Diaspora literature written by women: The cases of Esmeralda Santiago's América's Dream (1996) and Rosario Ferré's THL (1995) (The University of Manchester, 2015). 
nated" by the Spanish language and due to her subversive self-translation practice. In one of The House on the Lagoon storylines, Ferré elegantly theorizes about her self-translation practice, which is analyzed in this article.

Keywords: self-translation, linguistic hybridity, postcolonial literature, Puerto Rican literature, linguistic subversion.

\section{Le stratagème du faible: L'autotraduction comme subversion linguistique et patriarcale de l'auteure portoricaine Rosario Ferré}

\section{Résumé}

La subversion linguistique a été un outil révolutionnaire pour de nombreux écrivains afin de faire face au canon littéraire et à l'homogénéisation des différentes identités nationales en Amérique latine à différentes époques de son histoire. C'est dans ce contexte que l'on analyse la littérature de Rosario Ferré, qui fait partie de la Generación del 70 portoricaine et qui a encouragé des conceptualisations sur les identités hybrides portoricaines. Ces conceptualisations transgressaient l'identité nationale hispanique que certaines institutions et organisations politiques de l'île avaient officialisée en s'opposant aux tentatives colonialistes des États-Unis qui prétendaient assimiler les Portoricains sur les plans linguistique et culturel. Dans ce contexte littéraire, le cas de l'écrivaine Rosario Ferré est très spécial en raison de sa position politique et sociale, de son incursion particulière sur le marché littéraire américain en publiant en anglais «contaminé» linguistique et culturellement par l'espagnol et de sa pratique subversive de l'autotraduction. Dans une partie de l'intrigue de son roman The House on the Lagoon, Ferré se donne la permission de théoriser sur l'autotraduction, pratique que l'on analyse dans cet article.

Mots-clés : autotraduction, hybridité linguistique, littérature postcoloniale, littérature portoricaine, subversion linguistique. 


\section{Introducción}

En la literatura, la subversión lingüística y la autotraducción como herramienta subversiva son dos fenómenos que se pueden analizar desde diferentes ámbitos de estudio y a través de diferentes marcos teóricos. Sin embargo, en este artículo se aplicarán conceptualizaciones provenientes principalmente de dos campos de estudio - los estudios poscoloniales y los estudios de traducción - y se incluirán otras provenientes de la lingüística y los estudios de género. Esta selección responde, en el caso de los estudios poscoloniales, al desarrollo de las herramientas de análisis necesarias para explorar las condiciones de los sujetos colonizados, el carácter de su producción literaria y los efectos de esta última en su persona y en su entorno. En el caso de los estudios de traducción, es preciso señalar que su pertinencia en el análisis de los fenómenos que aquí se estudian recae en el hecho de que este campo de estudio ha reconocido la traducción como una actividad intrínsecamente política (Kumari, 2017, p. 166), por lo que a partir de la década de los noventa le ha prestado atención exponencialmente al rol de esta actividad en la construcción de discursos (Munday, 2017, p. 214) y al rol político de los traductores y las traductoras en la construcción del canon literario (Kumari, 2017, p. 166). En este escenario han surgido los "estudios de autotraducción" (Anselmi, 2012) como un campo de estudio que considera la autotraducción como "un fenomeno di crescente interesse per la comunità scientifica internazionale" (Sebellin, 2018, párr.8) y la inserta en un terreno de activismo social y cultural - "as it is embedded with historical, social, political and cultural struggles" (Castro, Mainer y Page, 2017, p. 78) - Esta interdisciplinariedad con la que se ha estudiado dicho fenómeno traductológico ha contribuido a que hoy por hoy la autotraducción sea una de las temáticas más abordadas dentro de los estudios de traducción, como lo demuestra el alto número de artículos científicos indexados en revistas de corriente principal, capítulos de libro, libros y ponencias en congresos dedicados a esta temática (cfr. Gentes, 2019).

Durante las primeras décadas del siglo $\mathrm{xx}$, Estados Unidos — que en 1898 había sustituido a España como poder colonial- trató de imponer el inglés para asimilar a los puertorriqueños al estilo de vida y a la cultura estadounidenses. En respuesta, los puertorriqueños defendieron la lengua española como expresión de su cultura y de su identidad, y siguieron siendo un pueblo hispanoparlante. Esta defensa lingüística representa un cambio importante, porque anteriormente los puertorriqueños no habían podido diferenciarse lingüísticamente de los españoles, pero ahora la lengua era un distintivo identitario frente al colonizador.

La manera violenta como Estados Unidos trató de imponer su lengua y su cultura tuvo como resultado la emergencia, en la década del treinta, de un movimiento literario hispanófilo que se convertiría en un movimiento literario canónico. En el contexto de la relación colonial entre la isla y Estados Unidos, este movimiento precedería a una generación de escritores y escritoras que en las décadas de los sesenta y los setenta usarían la literatura para subvertir, por medio de su uso de la lengua, conceptualizaciones homogeneizadoras de la identidad nacional puertorriqueña provenientes tanto del canon literario isleño como de la metrópolis estadounidense.

En este contexto, la tesis que sustentará este artículo es la existencia de una identidad nacional híbrida poscolonial, en conflicto con la identidad cultural y lingüística hispanófila oficializada históricamente por instituciones y organizaciones políticas y culturales, que 
puede identificarse claramente en las obras literarias, no solamente en su contenido y en los temas que abordan, sino también en cómo se utiliza la lengua como instrumento político que desafía el orden colonial.

\section{Hacia una conceptualización de la subversión lingüística}

En el marco de este trabajo se usa el concepto poscolonialismo para hacer referencia a los efectos culturales de la colonización (Ashcroft, Griffiths y Tiffins, 1998, p. 186), con base en el cual se pretende considerar el caso de Puerto Rico y su relación con los Estados Unidos. Los estudios poscoloniales buscan develar y deconstruir el daño infligido por los países colonizadores a los pueblos colonizados, sus identidades y sus culturas, e identificar las maneras como los marginados pueden recuperar su voz y escapar a la marginación a través de la construcción de identidades poscoloniales.

Es pertinente aclarar que el término "poscolonialismo", contrario a su versión compuesta, "post-colonialismo" y tal como ha sido ocupado por la crítica literaria a partir de la década de los setenta (Ashcroft, Griffiths y Tiffin, 1998, p. 186), no hace hincapié en si los países han alcanzado o no su independencia, sino que es un concepto más abstracto y con una mayor carga ideológica, dado que hace referencia a un periodo de tiempo más extenso: desde el comienzo del proceso de colonización hasta la época posterior a la independencia. Por otro lado, es fundamental recordar que Puerto Rico es formalmente un "estado libre asociado", aun cuando no cumple con lo establecido por las Naciones Unidas en el Principio VII de su Resolución 1541, el cual dispone que en la libre asociación los territorios deben tener "la libertad de modificar el estatuto de ese territorio mediante la expresión de su voluntad por medios democráticos" (Naciones Unidas,
1960, s. p.). En el ámbito judicial y criminal podemos encontrarnos con el hecho de que pese a la abolición de la pena de muerte en la isla en 1929, como consta en su constitución, aún se aplica en algunos casos por orden de la Corte Suprema de los Estados Unidos, que considera a Puerto Rico sujeto a la ley federal. Otro hecho que pone en evidencia el estatus colonial de este país es el carácter no vinculante de los referéndums que se han llevado a cabo en la isla en las últimas décadas, cuyos resultados no han tenido efecto alguno en su estatus, dado que solo el Congreso de los Estados Unidos tiene la potestad de modificar la naturaleza de la relación política entre ambos países, no así los puertorriqueños que por vías democráticas han expresado en innumerables ocasiones su parecer con respecto a esta relación. Otros académicos han recopilado datos adicionales acerca del estatus colonial de la isla bajo los Estados Unidos, pero por falta de espacio no se incluirán aquí sus hallazgos.

Uno de los debates centrales de estos estudios es si es posible o no que los colonizados se descolonicen, teniendo en cuenta el hecho de que los sujetos colonizados han sido educados por un sistema educativo colonial. No analizaremos a fondo este debate aquí, sino que presentaremos algunos conceptos que dan cuenta de las herramientas que los colonizados han utilizado para revertir su marginación a través de la construcción de discursos deconstructivos y subversivos. En este sentido, teóricos como Frantz Fanon (1967) han sustentado la agencia de estos sujetos a través de la deconstrucción del discurso del colonizador. Influenciado por este último, Edward Said va más allá al centrarse en la agencia que moviliza el subalterno utilizando la literatura como herramienta poscolonial. La estrategia narrativa ocupada por el colonizador para presentar al colonizado como un ser incapaz de gobernarse a sí mismo es la misma estrategia que este ocupa para 
"assert their own identity and the existence of their own history" (Said, 1993, p. xiii). Esta "cultura de resistencia" consiste en el uso de la ficción para apropiarse de la cultura colonial como parte de un proceso poscolonial (p. 34).

Los teóricos Homi Bhabha y Gayatri Spivak se centran también en el colonizado y en su habilidad para apropiarse del discurso del colonizador para resistir. Bhabha postula el concepto de "hibridez" como "the strategic reversal of the process of domination through disavowal", ya que esta "displays the necessary deformation and displacement of all sites of discrimination and domination" (1994, p. 159). Para Ashcroft, Griffiths y Tiffin, la hibridez es "the creation of new transcultural forms within the contact zones produced by colonization" (1998, p. 20). Junto con la hibridez, operaría la "apropiación", entendida como "the process by which the language is taken and made to 'bear the burden' of one's own cultural experience" (Ashcroft et al., 1989, p. 38). Este concepto es extremadamente relevante para la discusión de la subversión lingüística en el caso de Ferré, pues, como argumentaremos, se puede utilizar para describir su escritura en lengua inglesa, su uso del cambio de código o code switching y su práctica autotraductora.

Por otro lado, a diferencia de otros teóricos poscoloniales, Spivak (1988) examina el rol de la mujer colonizada en el sistema colonial y argumenta que ella se encuentra atrapada entre la opresión del colonizador y la opresión del hombre colonizado y cuestiona además al movimiento feminista hegemónico al señalar que el hecho de que no reconozcan los diferentes niveles de opresión que sufren las mujeres no heterosexuales, blancas y de clase media, constituye una falla en su intento por darle voz a todas las mujeres, porque en realidad no deconstruyen el sistema imperial. Esta perspectiva feminista sobre la mujer co- lonizada es especialmente relevante para analizar el fenómeno de la subversión lingüística en el caso de Rosario Ferré, porque a través de su obra ella respalda la afirmación de Spivak de que "[i]f, in the context of colonial production, the subaltern has no history and cannot speak, the subaltern as female is even more deeply in shadow" (1988, p. 28), lo que haría necesario estrategias aún más agresivas como las que se presentarán en este artículo.

Acerca de quienes producen su literatura en la lengua de su colonizador, el escritor indio R. K. Narayan (1979) afirma que esa estrategia les permite crear una tercera lengua y una tercera identidad, que desestabiliza tanto la lengua de partida como la lengua de llegada. En el proceso de escribir en un idioma que no es su lengua materna, los/as escritores/as tienen que decidir qué palabras dejarán en la lengua vernácula y qué palabras traducirán, pensando en su nueva audiencia. Esta estrategia, que implica no acercarle todo el contenido de la obra al nuevo lector, sino dejar algunas palabras, frases u oraciones en la lengua materna, puede crear una lengua escritural híbrida que a su vez, como señala el novelista y poeta martinicano Édouard Glissant, puede producir como resultado una literatura "opaca" que desafía la transparencia como vía de supresión de la diferencia para favorecer modos de escritura hegemónicos e intenta reemplazar al inglés como lengua central dominante (1989). Otra contribución importante de Glissant es su creencia de que los/as autores/as poscoloniales deben hacer uso de estrategias de traducción opacas, ya que, según él, "opportune obscurities in translation must be created" para evitar privilegiar estrategias de traducción que invisibilicen ${ }^{2}$ a las/os traductoras/es negándoles agencia (1997, p. 120). En este sentido, las traductólogas Hokenson y Munson aconsejan

2 Ver Venuti, 1995, sobre traducción e invisibilización. 
"to try to set preconceptions about equivalence aside, and to study each instance in its historical context", al analizar actos de traducción en contextos poscoloniales (2007, p. 9).

Cuando analizamos textos escritos por autoras/es que se autotraducen, debemos evitar hacer análisis que fusionen la identidad nacional con el uso de la lengua, ya que, al menos en el caso de Puerto Rico, estas perspectivas no se corresponden con la realidad lingüística poscolonial. Para poder analizar estos fenómenos lingüísticos subversivos en su justa perspectiva, la investigación sobre literatura bilingüe y autotraducciones debe buscar nuevos marcos teóricos que tengan en cuenta el hecho de que el monolingüismo no se ajusta a la realidad de la mayor parte de los países. En el caso del análisis de la actividad autotraductora, esta debe considerarse como una herramienta discursiva poscolonial utilizada para resistir representaciones occidentales mediante su alteración y desplazamiento (Gentzler, 2001, p. 176).

Debido a las particularidades contextuales de los sujetos que en contextos poscoloniales se sirven de estrategias de escritura subversivas, es necesario examinar el entorno en el que surgen los textos analizados, tal como han afirmado algunos teóricos y teóricas como Hokenson y Munson. Para poder examinar este entorno se tendrá en cuenta la tipología paratextual de Gérard Genette, ya que su propuesta releva la importancia de todos los "elementos paratextuales" que se encuentran en la "zone between the text and [the] off-text, a zone not only of transition but also of transaction", a la que el crítico literario llamaba "el paratexto" (1997, p. 2). No haremos aquí una revisión detallada del sistema de clasificación de Genette; sin embargo, en la metodología, utilizaremos sus categorías según sea pertinente.
Como se ha expuesto, la teoría poscolonial es el marco analítico más útil para analizar la literatura que contiene estrategias de subversión lingüística, en cuanto provee las herramientas conceptuales para entender las razones que instan a estos escritores y escritoras a servirse de ellas. Así, podemos definir la subversión lingüística como el uso de la lengua y sus recursos para deconstruir y desestabilizar discursos que crean representaciones homogeneizadoras de identidades, lenguas y culturas.

\section{Metodología}

Aunque el número de investigaciones que exploran el fenómeno de la subversión lingüística en la literatura ha aumentado considerablemente en las últimas décadas, aún existe una brecha investigativa debido a que mayormente se han investigado casos específicos, por lo que sus hallazgos no han trascendido los contextos literarios individuales.

Para explorar en qué consiste la subversión lingüística presente en narrativas literarias, este artículo identificará en primer lugar las estrategias de los escritores y las escritoras para implementarla. En segundo lugar, indagará en los efectos que tiene este tipo de subversión en la lengua, en la cultura y en la representación de las identidades híbridas de los sujetos que la implementan. Para ello se utilizan métodos de investigación cualitativos que incluyen un análisis textual y paratextual del corpus, constituido por la novela The House on the Lagoon (1995), ${ }^{3}$ de la puertorriqueña Rosario Ferré, y su autotraducción La casa de la laguna (1996). ${ }^{4}$ También se ocupan fuentes secundarias que constituyen los paratextos escritos por Rosario Ferré y los paratextos publicados por críticos y críticas literarias sobre Ferré y su obra.

3 En adelante $T H L$

4 En adelante $L C L$. 
Las fuentes secundarias de Ferré se detallan a continuación:

- "Cuando las mujeres quieren a los hombres" (1974)

- "On Destiny, Language, and Translation; or, Ophelia Adrift in the C. \& O. Canal" (1991)

- "On Bilingual Trespassing" (1996)

- "The Blessings of Being Ambidextrous" (1997)

- "Puerto Rico, U.S.A." (1998)

- "Familia e historia nacional" (2000)

- A la sombra de tu nombre (2001)

- Duelo del lenguaje/Language Duel (2002)

- Memoria (2012)

- Otros paratextos publicados por críticos literarios sobre Rosario Ferré y su obra

El análisis de estas fuentes es fundamental para examinar los elementos contextuales que rodean al texto literario y analizar cómo estos elementos se relacionan e interactúan con el texto, influenciando el significado que el lectorado extrae de él. Cabe mencionar que la mayor parte de los paratextos que se analizarán serán "epitextos", "mensajes que, $[\ldots]$, se encuentran afuera del libro, [...] (entrevistas, conversaciones) o comunicaciones privadas (cartas, diarios, y otras comunicaciones)". ${ }^{5}$ Estos serán o "previos" (anteriores a la publicación), "originales" (de publicación simultánea), "ulteriores" (posteriores a la publicación), "tardíos" (con republicación), o "póstumos" (posteriores a la muerte de la autora). Con respecto a la naturaleza de la "substancia" de los paratextos, se han analizado ambos paratextos: los "paratextos textuales", que "comparten el estatus lingüístico del texto", 6 y los "paratextos factuales", que "consisten no de un mensaje explícito [...] sino de un hecho cuya sola existencia, si es conocida por

5 Mi traducción. 6 Mi traducción. el público, le sirve de comentario al texto e influencia la manera en que es recibido". ${ }^{7}$ Considerando estos paratextos, se tomó en cuenta el contexto de Rosario Ferré, prestando especial atención a los paratextos factuales (trasfondo migratorio y familiar), y a las afirmaciones que contienen los epitextos sobre su relación con Puerto Rico. También se examinaron los elementos culturales y lingüísticos híbridos en los epitextos autorales que proveen información sobre su contexto como escritora y sobre su escritura en lengua inglesa, su identidad híbrida y su actividad autotraductora (biografías y entrevistas) (Genette, 1997, p. 5-7).

E1 análisis textual de las fuentes primarias toma en cuenta los siguientes elementos:

- La subversión narrativa presente en THL

- La inclusión de texto en español en THL

- La inclusión de texto en inglés en $L C L$

- Las estrategias de inclusión de texto en español en THL

- Las diferencias textuales entre THL y su autotraducción $L C L$

A modo de resumen, la subversión lingüística en el caso en cuestión se analizó a través de un análisis textual y de un análisis paratextual para explorar su relación con las intenciones de la autora y el efecto que tiene este fenómeno en su obra.

\section{El canon literario y el surgimiento de identidades híbridas en la situación de Puerto Rico}

Para entender el fenómeno de la subversión lingüística en el caso de la literatura puertorriqueña escrita en inglés durante las últimas décadas del siglo $\mathrm{xx}$, es necesario examinar la relación sociopolítica entre Puerto Rico y

7 Mi traducción. 
los Estados Unidos. Desde las primeras décadas del siglo $\mathrm{xx}$, y luego de que la isla pasara a manos de Estados Unidos como botín de guerra en 1898, este nuevo régimen colonial intentó asimilar lingüísticamente a los puertorriqueños. Sin embargo, este intento encontró una feroz resistencia cultural con fuertes valores hispanófilos, pues los puertorriqueños se negaron a deshacerse de lo que los diferenciaba de sus nuevos colonizadores: su lengua. De esta resistencia surgió en la década de los treinta un movimiento literario que se aferró al español como marcador identitario y que se caracterizó por presentar una cultura homogénea con una fuerte base patriarcal, sobre la base de "la gran familia puertorriqueña". Este concepto fue respaldado por valores pertenecientes a la clase dominante, que excluían elementos culturales asociados a la mujer, la clase trabajadora, la comunidad negra y la homosexualidad. En este contexto surgieron importantes instituciones culturales, como el Instituto de Literatura Puertorriqueña y la Biblioteca de Autores Puertorriqueños.

Aunque por cuestiones de espacio, no entregaremos aquí un análisis más profundo sobre la evolución de la literatura puertorriqueña, es importante tener en cuenta que esta generación treintista, cuyo impacto para Puerto Rico se puede comparar al impacto que tuvo la "Generación del 98" para España, instauró un canon literario con obras escritas en español que marginaría a los escritores y escritoras que comenzaron a escribir en inglés o a utilizar estrategias de escritura que incorporaban el inglés, como el cambio de código, tanto desde la diáspora en los Estados Unidos como desde la isla. Durante esta década y por los siguientes cuarenta años, incluso la literatura escrita desde la diáspora estadounidense se escribía en español, con algunas excepciones, como el caso de Arturo Alfonso Schoumburg, quien escribió en inglés sobre la contribución de los afroamericanos a la sociedad estadounidense, y el de Jesús Colón, un activista socialista y líder comunitario que durante los cuarenta y los cincuenta escribió una serie de cuentos en inglés sobre sus experiencias como inmigrante puertorriqueño negro. La literatura de Jesús Colón le abrió paso al movimiento Nuyorican, una nueva cepa de escritoras y escritores puertorriqueños, que influenciado por el aumento de la pobreza en la isla, el fracaso del programa industrial Operación Manos a la Obra, la emergencia de movimientos revolucionarios en Latinoamérica y las protestas contra la Guerra de Vietnam, entre otros eventos, propusieron nuevas perspectivas de análisis y propuestas literarias alternativas mediante la incorporación de estrategias de escritura innovadoras. Estas innovaciones representaron una ruptura con generaciones previas.

Es importante mencionar que este grupo de escritores y escritoras, que migró durante su infancia, hablaba español o espanglés en el ámbito familiar, como la mayor parte de los/as puertorriqueños/as que migraron a la metrópolis, y preservó una cantidad significativa de tradiciones culturales y sociales puertorriqueñas entrelazadas e influenciadas por la cultura estadounidense a pesar de publicar su obra en lengua inglesa desde los Estados Unidos. Algunas/os de las/los exponentes más representativos de este movimiento literario en los Estados Unidos son Piri Thomas, Nicholasa Mohr, Edward Rivera, Edwin Torres, Abraham Rodríguez, Judith Ortiz Cofer, Esmeralda Santiago y Alba Ambert en la novela, así como Pedro Pietri, Miguel Algarín, Miguel Piñero, Lucky Cienfuegos, Sandra María Esteves, Bimbo Rivas, Víctor Hernández y Jesús Papoleto Meléndez, en la poesía. La contribución de estos/as poetas —desde su participación en el Nuyorican Poets' Café- al movimiento literario de la diáspora estadounidense fue central, pues su producción logró 
reflejar fielmente la particular manera como los puertorriqueños de la diáspora neoyorquina se comunicaban en sus barrios. A través de su poesía, denunciaron la marginación que experimentaban los puertorriqueños en los Estados Unidos cuestionando así la idea del sueño americano. Las obras escritas y publicadas por puertorriqueños/as en la diáspora se caracterizaron por documentar las experiencias de migración, transculturación y adaptación de los miembros de su comunidad y, al igual que las de sus contemporáneos y compatriotas isleños, transformaron la lengua literaria del canon para describir su realidad y representar su hibridez lingüístico-cultural.

Cabe mencionar que otros medios, como las artes visuales, también sirvieron para expresar una identidad puertorriqueña híbrida, especialmente en el contexto del movimiento cultural Nuyorican. Uno de los ejemplos más emblemáticos de esta expresión identitaria lo podemos encontrar en la creación de la Puerto Rican Embassy en el año 1994. Este proyecto artístico, creado inicialmente por el dramaturgo Eduardo Figueroa en el 1979 con el concepto de "el Spirit Republic of Puerto Rico", fue retomado por Adál Maldonado y por el poeta nuyorican y miembro fundador del Nuyorican Poets' Café, Pedro Pietri, quienes conceptualizaron una identidad borrosa, desenfocada, a través de la toma de fotos intencionalmente desenfocadas para representar una forma de ser indefinida y cambiante, una identidad esquizofrénica producto de un trauma psicológico y emocional ocasionado por la colonización española en primera instancia y por la estadounidense después (como se cita en Estrin, 2012, párr. 9). Uno de los beneficios de tener una identidad de esta índole es que se puede pasar desapercibido, e infiltrarse de esa manera en la conciencia del colonizador para llevar a cabo sus actos de subversión (como se cita en En Foco, 2011, parr. 1).
Años después de la creación de este concepto Adál reflexionaría acerca de su proyecto subversivo sirviéndose del cambio de código para enfatizar el significado de sus actos artísticos: "Maybe nosotros no somos los que estamos fuera de foco maybe is the signs that we are receiving. Las direcciones de los centers of power; that's what's out of focus" (Blanco, 2011, párr. 17).

De esta manera, Adál y Pietri hacen una propuesta subversiva e innovadora para combatir la asimilación cultural que enfrentan como migrantes provenientes de un territorio colonial, ya que, en vez de afirmar su diferencia, en términos de identidad cultural, a través de la preservación de identidades "puras" hispanófilas, las afirman plasmando y reproduciendo la hibridez mediante sus actos de habla y su producción artística.

\section{Rosario Ferré: Su obra y su(b)versión}

En la sección anterior se hizo un breve recorrido por la literatura puertorriqueña del siglo xx, luego de la llegada de Estados Unidos a la isla, con especial énfasis en dos grandes etapas. La primera, que tuvo lugar durante las primeras décadas del siglo hasta aproximadamente la década del sesenta, terminó por establecer un canon literario, en defensa de una identidad propia diferente de la del nuevo colonizador, cuya influencia persiste hasta el día de hoy y que resaltó la herencia cultural y lingüística producto de la colonización española en detrimento de las tradiciones taínas, africanas y de sectores marginados de la sociedad puertorriqueña que no representaban los valores de la clase patriarcal dominante. La segunda etapa viene a desafiar ese canon literario hispanófilo, influenciada por un contexto económico y social producto de la situación colonial que convierte a los/as puertorriqueños/as en ciudadanos/as de se- 
gunda clase y que empuja a muchos de ellos a migrar a los Estados Unidos, tratando de escapar de la pobreza, pero que los enfrenta con una dura realidad que los empuja a desarrollar una identidad lingüístico-cultural diferente de la identidad estadounidense y de la identidad de las y los puertorriqueños que se quedan en la isla. Esta producción literaria presenta una identidad puertorriqueña compleja e híbrida que va a intentar subvertir la marginación de la cual fueron objeto sectores de la sociedad puertorriqueña, como las mujeres, los y las afrodescendientes, las disidencias sexuales y quienes migraron a la diáspora estadounidense. Para esto se va a servir de varias estrategias, muchas de las cuales se pueden apreciar en la literatura de Rosario Ferré, considerada como "la intelectual más importante de la literatura contemporánea de Puerto Rico" (Rivero, 2016, párr. 1).

Como plantean algunos acercamientos literarios feministas, el estudio de las ideologías políticas y de las experiencias de vida de quienes producen obras de ficción tiene una influencia significativa en su obra, aunque esta no necesariamente es determinante, por lo que debe considerarse un ejercicio productivo (Miller, 2009). En el caso de Ferré, al igual que en el de otras escritoras y escritores que se autotraducen, es importante examinar su literatura a la luz de su contexto personal, ya que las temáticas que aborda su obra, su selección de la lengua escritural, la direccionalidad de su autotraducción, su posicionamiento dentro del mercado y frente a los cánones literarios y las estrategias escriturales que implementan, parecen haber sido pensadas para actuar y tener un efecto en esa realidad.

Nacida en 1938 en Ponce, Puerto Rico, Rosario Ferré fue hija de Luis Alberto Ferré Aguayo, exgobernante de la isla (1969-1973) y próspero empresario, y de Lorenza Ramírez de
Arellano. Tuvo una infancia privilegiada, llena de lujos, como el contar con choferes privados, niñera personal y frecuentes viajes familiares a Europa y a los Estados Unidos, los que alimentaron su intelecto y avivaron su curiosidad. La biblioteca de su padre estaba llena de libros a los que no todos tenían acceso por estar en la lista de libros prohibidos por la iglesia católica. La mayor parte de ellos eran clásicos europeos y estadounidenses, ya que sus padres pensaban que "Europa era la fuente de toda cultura y civilización" (Ferré, 2012, p.93). Ferré comenzó a aprender inglés durante su enseñanza elemental bajo la tutela de curas marianistas estadounidenses y más tarde en el Colegio del Sagrado Corazón. A los trece años fue enviada a Danna Hall, un internado protestante en Massachusetts. Luego de terminar su educación secundaria, obtuvo un título en lengua inglesa y francesa en el Manhattanville College, de Nueva York, en la década de 1960 (Ferré, 2012, p. 14, 87, 88, 93 y 108). A los diecinueve años, se trasladó a Puerto Rico, se casó con el empresario Benigno Trigo, tuvo tres hijos y se transformó en un "ama de casa tradicional" (Ferré, 2012, p. 111-112), cumpliendo así con las expectativas de su familia. Así narra el conflicto entre sus propias expectativas y las familiares:

\footnotetext{
They wouldn't let me even consider a career as a journalist. Women weren't supposed to work at that time, so I got married and had three children. After ten years I got a divorce and then went to the University of Puerto Rico to do my master's degree in Spanish and Latin American literature (Perry, 1993, p. 85).
}

Luego de su divorcio, durante sus estudios en la Universidad de Puerto Rico, Ferré tuvo la oportunidad de contar a connotadas figuras como profesores, entre ellos al escritor puertorriqueño Enrique Laguerre Vélez, el peruano Mario Vargas Llosa y el uruguayo Ángel 
Rama Facal, quienes la instaron a ella y a su prima Olga Nolla a publicar la revista Zona de Carga y Descarga (en adelante "Zona"), que catapultó su carrera literaria (Ferré, 2012, p. 114). Tanto Nolla como Rama influenciaron grandemente a Ferré como escritora. La muerte de su madre, en 1970, hizo que Ferré sintiera la necesidad de escribir su primera novela, para no sufrir la misma suerte de su madre que vivió toda su vida silenciada por su rol de esposa (Ferré, 2001, p. 66-67). La vasta herencia recibida le permitió dedicarse exclusivamente a la escritura, que era lo que ella más disfrutaba hacer (Ferré, 2012, p. 77). Durante los dos años siguientes (1970-1972), Ferré actuó como primera dama, cuando su padre, fundador del partido defensor por excelencia de la incorporación de Puerto Rico como estado 51 de los Estados Unidos, el Partido Nuevo Progresista (PNP), fue electo como gobernador de la isla.

En esa época, Ferré se había distanciado de la burguesía con la que solía relacionarse en las ciudades de Ponce y San Juan y ahora se codeaba con artistas y escritoras/es que ejercieron mucha influencia en su vida y en su carrera literaria (García Pinto, 1988, p. 78). Así mismo, tuvo la oportunidad de leer a escritores defensores del ideal independentista, tales como José de Diego, Gautier Benítez y Llorens Torres (Ferré, 2012, p. 115). Este nuevo entorno hizo que Ferré cambiara su opinión con respecto a la situación política de la isla como muestra la siguiente cita: "Cuando salió Zona pasó otra cosa que fue muy importante para mí: cobré conciencia de nuestra situación política, y decidí que la independencia era la única solución posible para nuestro pueblo" (Ferré, 2012, p. 115). La revista dejó de imprimirse en el año 1976 debido al alto costo de publicación y al desgaste de las mujeres, quienes se encargaban de todo el proceso administrativo, mientras que los hombres solo se dedicaban a escribir (García Pinto, 1988, p. 83).
En 1975 Ferré conoció a su segundo marido, el escritor mejicano Jorge Aguilar Mora, y en 1976 ambos se trasladaron a México, donde publicó su primera colección de cuentos, $\mathrm{Pa}$ peles de Pandora (1976) (García Pinto, 1988, p. 78 ), centrada en "the multiple roles of women in Puerto Rican society" (Hintz, 1995, p. 14). Uno de los cuentos de esta primera colección fue el controversial cuento "Cuando las mujeres quieren a los hombres", una especie de homenaje a Isabel Luberza, una de las prostitutas más famosas de la ciudad de Ponce. Cuando este relato apareció por primera vez en Zona, en 1974, fue publicado junto a "La última plena que bailó Luberza", de Manuel Ramos Otero, un cuento sobre la misma mujer, pero narrado desde una perspectiva homosexual. "Cuando las mujeres quieren a los hombres" contenía lenguaje sexualmente explícito y sus protagonistas eran una viuda de alta alcurnia y una prostituta que deben convivir juntas en una misma casa que les heredó el hombre con el que ambas mantenían una relación amorosa, una como esposa y la otra como amante. Fue tanta la controversia que causó este cuento que Ferré fue acusada de ser "a traitor to her class and her gender", y algunos lectores decidieron echar a la hoguera esa edición de Zona, "because they thought it had to do with witchcraft" (Perry, 1993, p. 83). Esta edición causó tanto revuelo que, desde entonces y hasta la última edición, la revista se tuvo que mandar a imprimir a Nueva York. Otra razón por la que la revista Zona fue controversial fue el hecho de que en su segunda edición se expresara a favor del movimiento independentista. Cuando la prensa puertorriqueña se enteró de las tendencias independentistas de Ferré, sacó a colación su posición como hija del gobernador Luis A. Ferré que se estaba postulando para un segundo término. Una revista puertorriqueña llamada Avance publicó un artículo titulado: "Rosarito Ferré... O el otro mundo", que sugería que a pesar de que Rosario Ferré 
no había hablado públicamente sobre el independentismo, era 'un 'secreto' convertido en 'vox populi"” ("Rosarito Ferré... O el otro mundo", 1972, p. 5). Más tarde la misma revista publicó una carta enviada por Ferré en la cual confirmaba los rumores al decir que para escapar de "el limbo existencial" en el que estaban viviendo las y los puertorriqueños tenían que crear "una nación nueva e independiente" ("Rosarito Ferré confirma a Avance", 1972, p. 5). Posteriormente Ferré aclaró que no creía en ningún movimiento masivo y dejó entrever una actitud individualista hacia la política al decir que "[e]l escritor es un ser marginado que no debe identificarse con grupos políticos, yo ciertamente no pienso identificarme con grupo ninguno" (Borrás, 1972, p. 2, 4). Desde ese momento, fue considerada como "una intelectual proclive a la independencia de la isla" (Espinosa, 1998, p. 18).

A pesar de que su estancia en México había sido muy productiva literariamente, ${ }^{8}$ tuvo que regresar a la isla entre otras cosas por razones de salud. Su estancia en México también le dio la oportunidad de conocer a Elena Poniatowska y a otros escritores reconocidos y fue entonces que se dio cuenta de lo que significaba dedicarse a la escritura y confirmó que ella ya era una escritora. En 1981, Ferré comenzó sus estudios doctorales en la Universidad de Maryland; en 1983, se separó de su marido, y en 1985, obtuvo su título. En ese mismo año, se trasladó a Washington D. C., donde conoció a su tercer marido, el arquitecto Agustín Costa. Durante sus años en Estados Unidos, fue profesora en Berkeley, Johns Hopkins, Harvard, Rutgers y en la Universidad de Puerto Rico (Ferré, 2012, p. 122, 124 y 125). Al regresar a Puerto Rico en 1991 se casó con

8 Estando en México publicó su libro Sitio a Eros (1980), una colección de ensayos feministas, y El árbol y su sombra (1989), una colección de ensayos literarios.
Costa y continuó viviendo en la isla hasta su muerte, el 18 de febrero de 2016. Durante los últimos años de su vida y debido a su mal estado de salud, se mantuvo alejada de las letras.

\section{La subversión patriarcal a través de la subversión narrativa}

The House on the Lagoon se caracteriza por ser una obra que opera a varios niveles, incluyendo el narrativo y el lingüístico. Aunque este artículo se centrará en la subversión lingüística, también expondrá algunas otras prácticas complementarias que se pueden clasificar bajo la categoría de subversión narrativa.

Anteriormente se presentaron los elementos contextuales que contribuyeron a construir la autodefinida identidad híbrida de la autora, su relación con sus lenguas de escritura y con la práctica de la autotraducción. En esta sección se explorarán los elementos híbridos presentes en su obra y cómo utiliza una gran variedad de estrategias para subvertir concepciones homogéneas sobre la identidad lingüístico-cultural de la sociedad puertorriqueña.

En las primeras páginas, Ferré guía al lector a través de diferentes recursos tipográficos, como las itálicas, las negritas, las letras mayúsculas y la división de los capítulos, entre otros recursos, para que este se dé cuenta de que hay varias narrativas operando paralelamente en la novela. En la primera sección, que funciona como prólogo y se titula Quintín and Isabel's Pledge, Isabel narra los eventos que la llevaron a escribir el manuscrito que, como pronto descubriremos, es el que tenemos en nuestras manos. El manuscrito comienza con una introducción escrita por Isabel en la que narra un incidente violento que ocurrió entre Quintín, quien en esos momentos era su novio, y un enamorado suyo. Después de este incidente Quintín e Isabel deciden compartir sus 
historias familiares para "examine carefully the origins of anger" dentro de sus respectivas familias, para que esta ira no interfiriera con su felicidad. Este intercambio gatilla el interés de Isabel por escribir un manuscrito para preservarlas, pero, como ella misma dice al final de la introducción, "what I finally wrote was something very different" (Ferré, 1995, p. 5-6).

El uso de un marco narrativo, una narración dentro de otra, le permite a Ferré ubicar al personaje de Isabel, a través de inserciones textuales intercaladas en la novela/manuscrito, en una posición privilegiada como narradora extradiegética, cuya voz se encuentra en el primer nivel narrativo, y como narradora intradiegética, que ocupa el papel de narradora ficticia del manuscrito presentado al lector. Como personaje, Quintín no tiene una voz propia real, ya que, a pesar de que en el nivel narrativo extradiegético su perspectiva está presente a través de inserciones textuales que llevan su nombre. Estas inserciones no las narra él, sino un narrador omnisciente, que describe sus acciones e interacciones con el manuscrito y con Isabel. Para subvertir aún más la autoridad patriarcal, Ferré le da a este narrador omnisciente una identidad femenina. El género de la narradora de las inserciones en las que "habla" Quintín queda evidenciado cuando hace comentarios como "(like most men, he could barely find the socks in his own drawer without her help)" (Ferré, 1995, p. 146).

Una de las características principales de la novela es su gran número de personajes, como lo evidencia el árbol genealógico que incluye. A pesar de que los personajes principales son Isabel Monfort y Quintín Mendizábal, la manera como Ferré caracteriza a los personajes secundarios y construye sus historias le permite introducir temáticas y eventos históricos controversiales y representar sectores de la sociedad puertorriqueña que han sido margi- nados en la construcción oficial de la nación puertorriqueña y borrados de la historia oficial por quienes han estado en el poder.

Una de las temáticas principales que introduce Ferré en su obra es la construcción sesgada de la historia, la historia como construcción ficticia. Por medio de Isabel y Quintín, Ferré reconstruye la historia desde el punto de vista de los y las que han sido marginados/as. Estos personajes introducen la literatura y la historia como temáticas principales de la novela, para invitar a su audiencia a reflexionar sobre sus roles en la sociedad y sobre quiénes y cómo la construyen. De esta forma, Ferré no solo crea una dicotomía entre dos géneros y sus roles sociales, sino que además crea una dicotomía "entre géneros intelectuales, es decir, entre la literatura, representada por Isabel, y la historia, representada por Quintín" (Giusti, 1994, p. 130) y entre ideologías políticas sobre la relación entre Estados Unidos y Puerto Rico (estadidad versus independencia). Esta dicotomía le permite contar la historia desde diferentes puntos de vista, para mostrar cómo "everybody manipulates the truth to a certain extent" (Perry, 1993, p. 90).

En la primera de las inserciones textuales que narran las acciones de Quintín con respecto a Isabel y al manuscrito que ella está escribiendo, leemos la reacción de Quintín al darse cuenta de que su esposa está escribiendo un libro. No le molesta el hecho de que ella esté escribiendo un libro sobre la historia de sus familias, ya que él incentivaba su vocación literaria y “didn't want Isabel to be just another bourgeois housewife. He wanted her to amount to something, so he could be proud of her", sino que le preocupa el hecho de que lo esté escribiendo sola, sin pedir su opinión. Al comienzo de la inserción, Quintín parece asignarle igual valor a la historia frente a la imaginación, ya que considera que ambas son 
elementos importantes de la ficción, y parece darle crédito a Isabel por "her authentic efforts at writing fiction"; sin embargo, más adelante su preferencia por la historia se hace evidente cuando dice que la escritura "is not a serious occupation, like science or history". Al comparar la historia con la ciencia y al afirmar que "all writers interpreted reality in their own way", sin concluir que lo mismo se podría decir de la construcción de la historia, Quintín está desautorizando la perspectiva presentada por Isabel mediante su manuscrito en favor de su historia: la historia oficial escrita desde una perspectiva patriarcal (Ferré, 1995, p. 70-72).

A través de la narradora omnisciente, Ferré le deja saber al lector que la razón principal por la cual Quintín resiente la narración de Isabel es que en la misma ella es quien tiene el control, "imposing her opinions and making the decision; creating or destroying characters (and reputations!) at will", y a través de los personajes femeninos denuncia la opresión a la que estaban sujetas en la sociedad patriarcal en la que vivían. Quintín resiente el empoderamiento de Isabel, que con su narración invierte los roles de género, y comienza a pensar en cómo escribiría él la historia si él fuera el autor. Esto lo lleva a tomar una libreta y a escribir la "verdad histórica" (Ferré, 1995, p. 108-109). Este es su primer intento de modificar el manuscrito de Isabel, dejándole saber que lo ha leído, pero luego se arrepiente y se deshace de estas páginas y deja solo "a few commentaries here and there in pencil, in a tiny script which was almost invisible" (Ferré, 1995, p. 146). Estas páginas son importantes, porque en ellas Quintín reescribe la "verdadera" historia de los hermanos Monfort, Lorenzo, el abuelo de Isabel y su hermano Orencio y sobre porqué Orencio le ordena al capataz "to chop off Lorenzo Monfort's head” (Ferré, 1995, p. 112), con lo cual deja viuda a la abuela de Isabel, Abby Antongeorgi. Quintín conoció esta his- toria a través de uno de los vendedores de su empresa Gourmet Imports, quien a su vez la había escuchado de boca de Don Alvarado, el dueño de una tienda de abarrotes. A pesar de no tener conocimiento de los hechos de primera mano, Quintín decide que Don Alvarado es un "trustworthy man" (Ferré, 1995, p. 110), y que su historia tiene más credibilidad que la versión narrada por Isabel, simplemente por su condición de hombre. En la siguiente inserción, la tercera, Quintín muestra una vez más sus intentos por desacreditar la historia de Isabel, presentando su interpretación de algunos eventos históricos y políticos, como el ataque nacionalista contra el presidente Truman en el año 1950, el ataque nacionalista a la Cámara de Representantes de los Estados Unidos en 1954 y la masacre de Ponce ocurrida en 1937, con comentarios tales como: "she made another historical slip", "the truth was", "[t]his, of course was inaccurate", y "the lens through which the event was seen had been subtly altered", entre otros (Ferré, 1995, p. 149-152).

Mediante la exposición de Quintín sobre estos eventos, Ferré presenta la dicotomía política entre la estadidad, la cual él apoyaba, y la independencia, apoyada por Isabel. Al presentar como temática de la novela el estatus político de la isla, Ferré introduce el "language problem", que consiste en la negativa de los gobernadores en aprender a hablar español y en la imposición del inglés como lengua de instrucción en las escuelas públicas del país. Esta crítica a las prácticas colonialistas de los Estados Unidos se presenta junto a una reflexión acerca del inglés como la razón por la cual Puerto Rico es parte de "the modern world", mientras que otros países como Cuba, la República Dominicana y Haití viven aún en "the Middle Ages" (Ferré, 1995, p. 150). La narradora presenta esto como la opinión de Quintín sobre el tema, pero esta se relaciona directamente con una afirmación hecha por Ferré en 
la que sugiere que en el caso de Puerto Rico, ser un estado de los Estados Unidos es ser parte del mundo moderno. ${ }^{9}$ Esta reflexión sobre el estatus político de la isla y sobre las preferencias políticas de Isabel se podría interpretar como un comentario metatextual de Ferré sobre su propia decisión de escribir su novela, $T H L$, en inglés:

Would she have written her manuscript in English if she didn't think English was important? If she had written her novel in Spanish and published it in Puerto Rico, why, only a handful of people would read it! But if she published in the United States, thousands would read it. (Ferré, 1995, p. 150)

Otra temática muy presente en la narrativa de Ferré son los derechos reproductivos de las mujeres, la que presenta sirviéndose de dos personajes femeninos, Gabriela, la abuela materna de Isabel y Carmita, hija de Gabriela y madre de Isabel. En el caso de Gabriela, esta decide expulsar a su marido de su dormitorio matrimonial luego de dar a luz cada año por siete años, a pesar de la insistencia de su marido de que cumpliera con sus obligaciones matrimoniales, de su amor por él y de su disfrute del sexo. Gabriela no solo se rebela contra las convenciones sociales al defender el control sobre su propio cuerpo y su capacidad reproductiva, sino que se rebela contra la religión católica, a pesar de ser una católica practicante, cuando deja de ir a la iglesia al darse cuenta de que esta promovía una doble moral sexual, al condenar a las mujeres que disfrutaban del sexo, mientras que consideraba los deseos sexuales de los hombres como parte de su naturaleza. Más adelante, cuando se entera de que su hija Carmita está embarazada nuevamente luego de tres años de haber dado a luz a Isabel, Gabriela decide forzar a su hija

9 "Puerto Rico, U.S.A." The New York Times (19-31998). Artículo publicado tres años después de $T H L$. a abortar ofreciéndole una bebida que le ocasiona una gran hemorragia y la deja estéril, lo que le causa una tremenda depresión (Ferré, 1995 , p. 83, 87-88).

A través de la narración de la historia de estos dos personajes femeninos, Ferré se posiciona como una defensora del derecho de las mujeres a decidir sobre sus propios cuerpos, y denuncia el control que los hombres, el estado y la iglesia históricamente han ejercido sobre ellos.

\section{Caracterización híbrida de personajes}

A través de las temáticas que incluye en su obra literaria, original y autotraducida, de la caracterización lingüística y culturalmente híbrida de sus personajes y de la hibridez lingüística que caracteriza a $T H L$, Rosario Ferré rompe con representaciones homogeneizadoras de la identidad cultural puertorriqueña provenientes de Estados Unidos y de la isla.

Antes de identificar cómo presenta la autora de $T H L$ una representación híbrida de los puertorriqueños y de su cultura, es necesario establecer que en el contexto de Puerto Rico existen dos tipos de hibridez cultural. Por un lado, tenemos la hibridez cultural que surgió como consecuencia de la mezcla racial entre los taínos, indígenas que habitaban la isla antes de la llegada de los españoles, los españoles que colonizaron la isla en 1493 y mantuvieron como colonia a la isla hasta 1898, y los africanos llevados a la isla por los españoles durante la colonización para servir como mano de obra. Por otro lado, tenemos la hibridez que produjo la relación colonial entre Puerto Rico y los Estados Unidos. Este artículo se centrará en la segunda, ya que es la más presente en la obra de Ferré y la que nos sirve para entender su relación con las lenguas en las que escribe y su decisión de autotraducirse. 
En THL, Ferré evidencia la relación colonial entre Estados Unidos y Puerto Rico al construir una narrativa repleta de elementos de la cultura estadounidense en convivencia con elementos de la cultura puertorriqueña, lo cual evidencia una identidad cultural híbrida. Estos elementos cumplen la función de darle contexto al lector sobre el lugar donde se desarrolla la acción y le aportan a la novela el sabor del español que se habla en Puerto Rico.

A través de toda la novela podemos observar el papel central que ocupa la hibridez en la narrativa de Ferré. Desde las primeras páginas de la obra, la autora construye representaciones híbridas, la primera de las cuales es la descripción del lugar en el cual Buenaventura, el padre de Quintín, construye la primera casa de la laguna. En este lugar "the mangrove swamp met the private beach of the lagoon" $y$ los animales que allí se pueden encontrar son descritos como "amphibious and terrestrial" a la misma vez y viven "half immersed in the mud, half encrusted in the mossy cartilage of the wood". Está representación espacial de la hibridez también está presente en el capítulo 2 , en el que se describe la parte colonial de la ciudad de San Juan a la cual Buenaventura llega el 4 de julio de 1917. Aquí podemos apreciar por un lado la presencia material de los Estados Unidos en la isla, barcos anclados en la bahía con nombres como "the Mississippi and the Virginia", la Oficina de Correos Federal, la parada del 4 de julio, la Cruz Roja Americana y el domo de El Capitolio, "an exact copy of the one Thomas Jefferson built at Monticello", y por otro lado a los puertorriqueños con sus sombreros de paja, símbolo del campesino (el jíbaro), participando de las típicas peleas de ga1lo. La imagen de la Oficina de Aduanas Federal, pintada de color rosa con "guava colored pinnacles on the roof", y la venta simultánea de hot dogs y de guarapo de caña, una bebida muy tradicional para los puertorriqueños, son el golpe de gracia que utiliza Ferré para fijar, desde el comienzo, una identidad cultural lejos del purismo presente en el canon literario (Ferré, 1995, p. 9, 10, 16-18, 20).

A esta representación espacial se le puede sumar como estrategia de escritura la construcción de personajes híbridos, como el de Abby, la abuela de Isabel, quien a pesar de ser independentista, atesora su catálogo de Sears ${ }^{10}$ y su pasaporte estadounidense que le permiten viajar a los Estados Unidos sin necesidad de contar con una visa (Ferré, 1995, p. 183). Otra estrategia de Ferré para mostrar una identidad cultural y lingüística bifurcada es la incorporación de la temática de la escritura en inglés, desde la isla, a través de uno de los personajes principales de la obra, Isabel, quien escribe su narrativa en inglés, tal como lo hace la autora de la obra que tenemos en nuestras manos, lo que destaca la relación de los puertorriqueños con esta lengua.

\section{Hibridez lingüística}

THL también presenta la identidad híbrida de Ferré a través del uso de lenguaje lingüísticamente híbrido. Ferré escribe su obra en inglés, pero en un inglés plagado de palabras, frases y oraciones enteras en español que lo distinguen de un inglés estandarizado. En contraste con obras de otras escritoras latinoamericanas bilingües, como Sandra Cisneros, Esmeralda Santiago o Julia Álvarez, quienes incorporan el lenguaje híbrido como temática en sus novelas, este recurso le sirve a Ferré para contextualizar al lector acerca del lugar en el que se desarrolla la acción de la novela y para darle a la narrativa el sabor del español que se habla en la isla. A continuación se presentan algunos ejemplos:

10 Sears es una cadena de almacenes estadounidense con presencia en Puerto Rico desde los años sesenta. 
A. "from time to time one could even see a tiger-eyed guaraguao, the nearly extinct local eagle" (Ferré, 1995, p. 10).

B. Slowly but surely, however, a bit of juicy gossip would slip out, or a risqué joke or expression which could only be rendered in Spanish: "Estaba más jalao que un timbre e guagua" (He was as drunk as a skunk); or "Éramos demasiados y parió la abuela" (There were already too many of us, and then Grandma got pregnant) (Ferré, 1995, p. 94).

C. "Father and Mother met at Ponce's fiestas patronales for the Virgen de Guadalupe" (Ferré, 1995, p. 140).

D. "Abby was defiantly Independentista" (Ferré, 1995, p. 182).

En algunos de estos ejemplos, Ferré construye una lengua subversiva que desestabiliza la lengua inglesa, pero hace uso también de estrategias de escritura domesticadoras que amortiguan el efecto de su subversión, tales como la explicitación (ejemplo A), el uso de préstamos o palabras que ya han sido incorporadas al inglés (ejemplo D), la traducción (ejemplo B), la adición de información contextual (ejemplo C). Estas estrategias favorecen al lectorado angloparlante, ya que le brindan herramientas para que pueda descifrar el significado de las palabras, frases y oraciones en español, sin tener que consultar un diccionario.

Sin embargo, en otros casos, como se puede observar en los ejemplos incluidos a continuación, Ferré favorece al lectorado bilingüe al incluir palabras y frases en español sin proveerle ayuda al lectorado angloparlante, lo que extranjeriza el texto.

A. "Usually there wasn't much to sell - a couple of red snappers; a spiny chapin, good for only one empanadilla" (Ferré, 1995, p. 133).

B. "The full moon is the godmother of all mayomberas" (Ferré, 1995, p. 134).
C. "papier-mâché masks for Vegigante costumes" (Ferré, 1995, p. 141).

D. "one of the local political caciques" (Ferré, 1995 , p. 184).

E. "that's why you could describe Rebecca with such gusto" (Ferré, 1995, p. 189).

Con la hibridación de la lengua inglesa, Ferré subvierte el valor hegemónico de la lengua mediante la apropiación lingüística para comunicar una identidad nacional híbrida. Como afirman Le Page y Tabouret-Keller en la contraportada de su libro Acts of Identity (1985, contraportada), "[w]ith every speech act all individuals, to a greater or less extent, an 'act of identity', revealing through their personal use of language their sense of social and ethnic solidarity or difference". La decisión de Ferré de escribir y publicar su obra en inglés se podría considerar como un acto de asimilación cultural, sin embargo, la inserción de palabras, frases y oraciones completas en español, aunque en algunos casos utilice estrategias domesticadoras, es un "acto de identidad" destinado a la expresión de una identidad híbrida bilingüe y debe considerarse como un acto subversivo de apropiación lingüística.

En su autotraducción de $T H L$, La casa de la laguna, Ferré implementa los mismos recursos lingüísticos al incluir texto en inglés como muestran los siguientes ejemplos, pero en este caso el inglés está presente en forma de nombres de instituciones y organizaciones que son parte de la narración de la relación entre Puerto Rico y los Estados Unidos.

A. "cuatro mil copias del First Reader in English" (Ferré, 1996, p. 104).

B. "el National Labor Relations Act" (Ferré, 1996, p. 135).

C. "se graduó en la Boston University y empezó a trabajar con su padre en la Gourmet Imports" (Ferré, 1996, p. 349). 
D. "a tono con el american way of life" (Ferré, 1996, p. 350).

E. "las recetas del Boston Cooking School Book" (Ferré, 1996, p. 350).

F. "el Carnegie Library Ladies Club, el Red Cross Ladies Committee" (Ferré, 1996, p. 350).

Como ha quedado evidenciado, Ferré construye lingüísticamente una identidad híbrida al incluir palabras y frases en español en su escritura en inglés. Si bien es cierto que la autora acompaña estas instancias de cambio de código con estrategias como la explicitación, la traducción, la adición de información contextual, que son consideradas como estrategias de amortiguación que domestican el texto al tener en cuenta al lectorado monolingüe del inglés, también es cierto que en ocasiones implementa el cambio de código de manera más agresiva, sin apoyarse en estrategias amortiguadoras por lo que el lectorado anglo se ve en la obligación de consultar un diccionario para poder descifrar el contenido de las palabras o frases en español. Es por eso que, aunque en $T H L$ esta estrategia no es tan agresiva como en otras obras escritas en inglés por otros y otras puertorriqueñas, como es el caso de Esmeralda Santiago y su novela America's Dream (1996), se puede considerar como una estrategia subversiva.

$\mathrm{Al}$ reescribir en inglés una narración que fue pensada y escrita originalmente en español, ${ }^{11}$ Ferré construye una representación de la identidad puertorriqueña diseñada para ser leída por un "otro", el lector angloparlante. Esta identidad es híbrida, no solo porque fue originalmente construida en español, incorporada luego en un texto escrito en inglés, la lengua del colonizador, y finalmente reescrita/retraducida al español, sino también porque la línea narrativa a través de la cual se construye,

11 Ver Irizarry 2001, artículo que evidencia el proceso de escritura de Ferré en el caso de $T H L$. evidencia los eventos históricos que unen a Puerto Rico y a los Estados Unidos y las consecuencias que esta relación ha tenido en la idiosincrasia puertorriqueña y, más aún, porque estos hechos no se narran utilizando un inglés estándar, sino un inglés híbrido con claras características poscoloniales.

\section{La autotraducción como subversión}

Para Ferré, "[1]a obra de arte es todo, [...] todo está identificado y es inseparable" (Ferré, 2000, p. 124). Bajo esta lógica, y teniendo en cuenta el conjunto de todas las autotraducciones de Ferré, se puede argumentar que la autotraducción que hace Ferré de su novela THL es parte de un mismo proyecto (Mendez-Clark, 2000, p. 396).

Desde 1978, la autotraducción ha sido parte del proyecto literario de Ferré. Al comienzo de su ejercicio de autotraducción, escribía y publicaba sus obras en español seguidas de la publicación de sus respectivas autotraducciones al inglés, como lo evidencian sus obras Papeles de Pandora (1976)/ The Youngest Doll (1979), Maldito amor (1985)/ Sweet Diamond Dust and other Stories (1988), y La batalla de las vírgenes (1993)/ The Battle of the Virgins (1994). En 1995, cambia la direccionalidad de sus autotraducciones con la publicación de $T H L$, su primera obra escrita originalmente en inglés, y su subsiguiente autotraducción al español, LCL (1996). A esta autotraducción le seguirían Eccentric Neighborhoods (1998)/Vecindarios excéntricos (1998), Flight of the Swan (2001)/El vuelo del cisne (2002) y Language Duel/Duelo de lenguaje (2002).

Una de las problemáticas que comúnmente rodean a la autotraducción como actividad literaria es si un texto autotraducido es un texto original o si por el contrario se debe considerar como obra secundaria con valor derivativo. Ferré se ha expresado sobre esta problemática 
mediante reflexiones acerca de la relación entre escritura y traducción y a través de la trama de su novela. Como lo indica la contracarátula, THL fue escrita originalmente en inglés. Sin embargo, Ferré ha mencionado en varias entrevistas que la novela es una traducción y una expansión de un cuento corto que ella había escrito anteriormente en español, pero que nunca publicó (Ferré, 1997, p. 63; 2000, p. 95). La explicación de Ferré sobre la génesis de $T H L$ la convertiría, junto a su autotraducción, en traducciones de un texto inexistente (Irizarry, 2001). Este argumento parece ser irrelevante para la escritora, ya que como ella misma ha afirmado "tanto [sus] libros en español como [sus] libros en inglés son originales", debido a que " $[u]$ na idea puede nacer en una lengua, y al pasar a otra se adensa, se estira, se enriquece o se clarifica" (Ferré, 2001, p. 177).

En su ensayo "On Destiny, Language, and Translation; or, Ophelia Adrift in the C. \& O. Canal" (1991), Ferré relaciona su reconciliación con su identidad híbrida, su necesidad de escribir tanto en inglés como en español y su actividad autotraductora. Además, se pregunta si " $\mathrm{i}[\mathrm{e}] \mathrm{s}$ posible traducir un texto literario cuando nos enfrentamos a las enormes diferencias culturales en las cuales todo lenguaje se encuentra incrustado?" (Ferré, 2001, p. 156). Luego de examinar varias teorías filosóficas sobre la lengua, dice estar de acuerdo con la postura de George Steiner al concluir que "real translation is impossible and that what passes for translation is a convention of approximate analogies" (Steiner, 1998, p. 77). Esta declaración sobre la imposibilidad de la traducción es consistente con la opinión de Ferré de que tanto sus novelas en español como sus obras en inglés son obras originales.

Las autotraducciones o recreaciones de Ferré han sido criticadas por ser demasiado liberales y por incluir demasiadas adiciones y otros cambios substanciales especialmente cuando escribe o se autotraduce hacia el inglés. Muchas y muchos estiman que estas concesiones van dirigidas al lectorado angloparlante (Jaffe, 1995 y Salgado, 1998). A pesar de que no me corresponde hacer juicios de valor respecto a las prácticas domesticadoras de Ferré, puedo entender por qué la crítica literaria sospechaba de las intenciones tras los cambios implementados por Ferré en sus autotraducciones, especialmente si se toma en cuenta su cambio de parecer con respecto al estatus político de la isla, ocurrido en 1998. Uno de los argumentos que brinda Ferré para explicar este cambio es que "conditions have changed" y que la estadidad no representaría una amenaza para la cultura y la lengua de la isla, porque el "bilingualism and multiculturalism are vital aspects of American society". También argumenta que Puerto Ricans "no longer need fear that 'el otro' (the other), will swallow us up" because they "have become the other" (Ferré, 1998, pár. 10-13).

A pesar de que este artículo no pretende evaluar la equivalencia en la autotraducción de Ferré, es necesario identificar las diferencias textuales que existen entre ambos textos en la búsqueda de información que ayude a formular hipótesis sobre las razones que la impulsaron a autotraducirse. Cuando empecé a comparar el texto de partida escrito en inglés con su traducción, me di cuenta de inmediato de que la versión inglesa incluía texto que había sido omitido en la versión española de la novela. Un ejemplo de esto es la omisión de algunos versos de la canción "Quiéreme mucho":

\footnotetext{
Versión inglesa: "He went on sitting on the ground, singing, 'Love me always,/sweet love of my life./ You know I'll always adore you./Only the memory of your kisses/will ease my suffering,' until he fell unconscious on the sidewalk." (Ferré, 1995, p. 4)
} 
Versión española: "Permaneció sentado en la acera, cantando Quiéreme mucho hasta que se desplomó inconsciente sobre el piso de ladrillos salpicado de sangre." (Ferré, 1996, p. 16)

Otro ejemplo de diferencia textual, pero a la inversa, se puede apreciar en la descripción sobre las aceitunas que importaba Buenaventura desde Sevilla, cuya versión española es mucho más detallada:

Versión inglesa: "There he stored his wines; the ruby-red hams he began to import form Valdeverdeja, his hometown; [...] and the exquisite Moorish olives from Seville." (Ferré, 1995, p. 12)

Versión española: "Allí almacenaba sus vinos; los jamones que empezó a importar de Valdeverdeja, su pueblo natal; [...] y las exquisitas aceitunas aliñadas de Sevilla — rellenas de pimiento morrón, cebollín o almendra-, cuyos ojillos verdes con pupilas rojas y blancas tanto lo alegraban cuando las veía alineadas en sus tarros sobre los estantes". (Ferré, 1996, p. 24)

Este último ejemplo en el cual en la versión española Ferré hace una adición, está en consonancia con el estilo barroco que la escritora admite tener cuando escribe en español; ${ }^{12}$ sin embargo, la omisión de versos en la transcripción de la canción "Quiéreme mucho", responde a un intento consciente de Ferré por domesticar el texto (Venuti, 1995). De esta manera le facilita al lectorado angloparlante la comprensión del texto y de la cultura e identidad que este presenta. A pesar de que, por un lado, Ferré parece domesticar el texto para favorecer al lectorado anglo al implementar adiciones y omisiones, por otro lado, como se mostró anteriormente, deja una cantidad significativa de referencias culturales en español, con y sin traducciones al inglés, para que el

12 "Escribir en inglés me ha ayudado, porque, en español, yo soy muy barroca. Me regodeo mucho en las descripciones" (citada en Castillo García, 2005, p. 243). lectorado nunca pierda la perspectiva de dónde se desarrollan los eventos que se narran. Esta estrategia también sirve para darle la oportunidad a la diáspora puertorriqueña de saborear su lengua materna y de identificarse con el texto a otro nivel.

A través de las adiciones y omisiones que implementa en su autotraducción, Ferré domestica el texto de partida para su audiencia angloparlante. Al parecer, al encontrarse en la "zona de contacto", entre dos orillas, las corrientes marinas la atraen hacia la cultura dominante porque, como afirma Mary Louise Pratt, existen "highly asymmetrical relations of domination and subordination" entre las dos orillas (1991, p. 4). Según el argumento que presenta la investigadora Joyce Tolliver en el resumen de su artículo "Rosalía between Two Shores: Gender, Rewriting and Translation", la traducción "is always implicated in relationships of cultural dominance and subordination" (2012, p. 33), por lo que las estrategias traslativas domesticadoras de Ferré no deben considerarse fuera de esta premisa. Su paternalismo hacia la cultura dominante que evidencian sus estrategias traslativas para facilitarle a la audiencia anglo la comprensión del texto debe entenderse en el contexto de la relación colonial entre Puerto Rico y Estados Unidos.

Ferré justifica las diferencias entre los dos textos al argumentar que "in translating one's own work it is only by betraying that one can better the original" (Ferré, 1991, p. 162), lo que le permite categorizar ambas obras como obras literarias originales. ${ }^{13}$ Como afirma Bo Byrk-

13 Estas diferencias textuales han sido analizadas por Suzanne Hintz (1995), Janice Jaffe (1995), Jennifer Beatson (1998), Mary Ann Gosser (1999), Ronald Méndez-Clark (2000), Lieve Behiels (2001), Frances Negrón-Muntaner (2004), Simona Cocco (2005) y Gema Soledad Castillo (2005). 
jeland en su tesis doctoral, lo que hace Ferré entre otras cosas es poner en tela de juicio la validez de la dupla original/copia (2014). La autora confirma este argumento cuando dice categóricamente, refiriéndose a sus libros y a sus autotraducciones, que "los dos son originales" (Negrón, 2016, párr. 46). A esta afirmación añade que "el escrito en inglés salió primero por razones prácticas, porque si se publicaba en inglés primero, podía entrar al mercado internacional. Si se publicaba como una traducción del (o al inglés), entonces no le daban la misma crítica, no aparecía en los medios. Pero en realidad, yo siento que es original tanto en inglés como en español." (párr. 46).

Prueba adicional de la intención de Ferré de desestabilizar el estatus autoral de sus textos es el rol que juegan las nociones binarias de "original" y "copia" en la trama de su novela. En su novela Ferré parece crear una metáfora sobre la traducción a través del personaje de Pavel, un arquitecto polaco contratado por Buenaventura para construir la primera casa de la laguna. Isabel clasifica el plagio de Pavel de los diseños arquitectónicos de Frank Lloyd cuando construye una iglesia en Jacksonville como una "exact copy" del trabajo de Wright mientras que Pavel se refiere a "su" diseño como una "faithful re-creation", "not a mere copy". Más adelante, al final del capítulo seis, Isabel se refiere al diseño de Pavel de la casa de Buenaventura como "something truly original", pues a pesar de haber usado uno de los diseños de Wright como modelo, había añadido "many new elements which would make the house more in keeping with life in the tropics". La fiel recreación "stone by stone" (Ferré, 1995, p. 41, 48, 49) del trabajo de Wright es una alegoría de la traducción "palabra por palabra" mientras que el diseño modificado que Pavel creó para Buenaventura teniendo en cuenta el entorno en el que se iba a construir la casa sería una metáfora para la traducción "sentido por sentido". Si seguimos la lógica de este par de metáforas, para que Pavel pudiera construir una casa tan bella como la que quería construirle a la esposa de Buenaventura, de quien se había enamorado, tenía que modificar el diseño de Wright en vez de hacer una copia "stone by stone" como había hecho anteriormente. Para que su casa fuera tan bella, tenía que crearse incorporando el contexto donde se construiría la nueva edificación. Estas metáforas podrían representar la defensa de Ferré de las adiciones y omisiones que incluye en sus autotraducciones. Como sugiere Boyd Carrière en su tesis doctoral, "Pavel is usurping Wright's authority and claiming it for his own when he surpasses his former master's designs" (Boyd Carrière, 2007, p. 191). Con su acto de autotraducción, Ferré hace algo similar. En su autotraducción hay una apropiación de los derechos de autor. La traducción, una actividad que ha sido considerada pasiva, invisible y secundaria, se transforma en una actividad activa, visible y primaria, y el resultado es una versión casi nueva por derecho propio. Con su acto, Ferré subvierte la relación tradicional entre autor y traductor, entre obra literaria original y obra traducida.

El desafío de Ferré a la autoridad textual a través de la subversión de los conceptos "autor" /"traductor", dobla su autoridad y es congruente con su proyecto feminista. Como lo demuestran las temáticas que incluye en su obra y las estrategias que en ella implementa, la escritura es para Ferré una herramienta fundamental contra el patriarcado (Caballero, 1999 , p. 89, Castillo, 2006, p. 18). Esta subversión también está presente en su actividad autotraductora en la medida en que a través de esta estrategia lingüística y traslativa Ferré presenta un claro desafío a la autoridad y gana agencia en una sociedad que por mucho tiempo la valoró por ser la hija de Luis A. Ferré. 


\section{Conclusiones}

De los análisis presentados se desprende que a través de su actividad autotraductora bidireccional (español-inglés e inglés-español), y de sus expresiones sobre la traducción, la escritura y la identidad puertorriqueña, Ferré quiere comunicar cómo ambas lenguas son parte esencial de su identidad, validando así una identidad cultural y lingüística híbrida. De este modo, la autotraducción funciona como una herramienta poscolonial para la afirmación de la hibridez cultural, pues le permite a Ferré expresar su identidad híbrida y el contexto híbrido desde el cual escribe, subvirtiendo conceptos homogeneizadores de la identidad nacional y los cánones literarios de Puerto Rico y de los Estados Unidos. Por otro lado, la manera como ejerce su actividad autotraslativa le permite a Ferré hacerse visible no solo como autora, sino también como mujer traductora dentro de una disciplina que ha impuesto prácticas patriarcales, y no cualquier traductora, sino como una traductora con una identidad híbrida proveniente de un contexto colonial que divide sus lealtades.

La autotraducción es parte esencial de la agenda de Ferré, porque la utiliza como un dispositivo literario adicional que le permite crear una obra bilingüe transcultural con el objetivo de presentar una identidad puertorriqueña profundamente marcada, tanto cultural como lingüísticamente, por la experiencia colonial de la isla, primero con España y luego con Estados Unidos. Al igual que otras escritoras y otros escritores de su generación, Ferré explora a través de su obra las particularidades de la identidad puertorriqueña y siente la necesidad de expresarse en las dos lenguas que la definen lingüísticamente. Esta expresión bilingüe cumple además la función de darle acceso a su obra a las y los puertorriqueños que viven en la isla, así como a quienes viven en los Estados
Unidos y han perdido su lengua en el proceso de adaptación a su nueva situación migratoria. El hecho de que en la obra de Ferré la autotraducción no sea una práctica aislada, sino que haya estado presente en su trabajo por más de veinte años, también evidencia la intención de presentar una identidad puertorriqueña híbrida mediante esta práctica.

A través de la escritura en inglés, la hibridez lingüístico-cultural y la autotraducción, que al presentar una obra desplegada en dos lenguas da cuenta de una identidad bifurcada, Ferré propone estrategias alternativas de resistencia a la asimilación, donde no se presenta el uso de la lengua española como único marcador identitario, sino que se afirma y valida la hibridez de la identidad puertorriqueña ante intentos puristas de erradicarla e invisibilizarla. Esta identidad híbrida es subversiva en la práctica, porque desestabiliza la autoridad y el estatus canónico del inglés como lengua colonial y contrarresta conceptualizaciones homogeneizantes de la identidad puertorriqueña.

El hallazgo principal de la investigación en la que se basa este artículo es que efectivamente la traducción puede ser un acto poscolonial si tomamos en cuenta la existencia de profundos vínculos entre el contexto sociopolítico, la lengua, la cultura, la identidad, el poder y la traducción. En el caso que nos ocupa, esta práctica está firmemente relacionada con el uso de la hibridez para afirmar una identidad nacional marcada por su historia y por un ir y venir entre dos lenguas y dos culturas que a su vez son intrínsecamente híbridas.

\section{Referencias}

Anselmi, S. (2018). On Self-translation: Meditations on language. Milán: LED Edizioni Universitarie. 
Ashcroft, B., Griffiths, G. y Tiffin H. (1998). Key concepts in post-colonial studies. Londres: Routledge.

Ashcroft, B., Griffiths, G. y Tiffin H. (1989). The empire writes back: Theory and practice in post-colonial literature. Londres: Routledge. DoI: https://doi. org/10.4324/9780203402627

Bhabha, H. (1994). The location of culture. Nueva York: Routledge.

Blanco, L. (2011, 21 de agosto). Un mundo fuera de foco: Entrevista a Adál Maldonado [Entrada en blog]. En Metacultura. Recuperado de http://lisablanco.blogspot. com/2011/08/un-mundo-fuera-de-foco-entrevista-adal.html

Borrás, G. (1972, 1 de octubre). La liberación de Rosario Ferré. El Mundo, p. 1-5.

Byrkjeland, B. (2014). The reinvention of the original: The self-translations of Maria Luisa Bombal and Rosario Ferré [Tesis doctoral]. Universidad de Bergen, Noruega. Recuperado de http://bora.uib.no/handle/1956/7847

Caballero, M. (1999). Ficciones isleñas: Estudio sobre la literatura de Puerto Rico. San Juan: Universidad de Puerto Rico.

Carrier, B. (2007). Displacement and the text: Exploring otherness in Jean Rhys's Wide Sargasso Sea, Maryse Conde's La migration des coeurs, Rosario Ferrés The house on the lagoon, and Tina de Rosa's Paper Fish [Tesis doctoral]. Louisiana State University, Estados Unidos. Recuperado de https://digitalcommons.lsu.edu/cgi/viewcontent. cgi? article $=1464 \&$ context $=$ gradschool_ dissertations

Castillo, G. A room/voice of one's own: La recuperación de la voz de dos heroínas ferrerianas, Gloria Camprubí e Isabel Monfort. Revista de Estudios Hispánicos, 33(1), 17-37.

Castillo, G. (2005). Entrevista a Rosario Ferré: in between dos worlds. Centro Journal, 17(2), 232-247.
Castro, C., Mainer S. y Page, S. (Eds.) (2017). Self-translation and power. Negotiating identities in European multilingual contexts. Londres: Palgrave Macmillan. DoI: https:// doi.org/10.1057/978-1-137-50781-5

Danicattan. (2011, 20 de julio). Print Program Highlight: Adal's Memorias Olvidadas [Entrada en blog]. En En foco inc. Recuperado de https://enfoco.org/2011/07/20/ print-program-highlight-adals-memorias-olividadas/

Espinosa, J. (1998, 31 de julio). Por qué hiciste eso, Agapito. El Mundo. Recuperado de http://www.el-mundo.es/1998/07/31/ internacional/31N0080.html

Estrin, J. (2012, 24 de agosto). Puerto Rican identity, In and out of focus. The New York Times. Recuperado de https://lens.blogs. nytimes.com/2012/08/28/an-artistssearch-fo-puerto-rican-identity/

Fanon, F. (1967). Black skin, white masks (C. L. Markmann, trad.). Nueva York: Grove.

Ferré. R. (2012). Memoria. San Juan: Callejón.

Ferré. R. (2002). Duelo del lenguaje/Language duel. New York: Knopf Doubleday Publishing Group.

Ferré. R. (2001a). A la sombra de tu nombre. Buenos Aires: Alfaguara.

Ferré. R. (2001b). Flight of the swan. New York: Farrar, Strauss \& Giroux.

Ferré. R. (2000). Familia e historia nacional. En W. Pino-Ojeda (ed.), Sobre castas y puentes: conversaciones con Elena Poniatowska, Rosario Ferré y Diamela Eltit (p. 77-135). Santiago de Chile: Editorial Cuarto Propio.

Ferré. R. (1998). Eccentric neighborhoods. Nueva York: Farrar, Strauss \& Giroux.

Ferré. R. (1998, 19 de marzo). Puerto Rico, U. S. A." The New York Times, A21.

Ferré. R. (1997, 12 de enero). The blessings of being ambidextrous. The San Juan Star, 8-9.

Ferré. R. (1996). La casa de la laguna. Buenos Aires: Emecé. 
Ferré. R. (1996, 5 de mayo). On bilingual trespassing. The San Juan Star.

Ferré. R. (1995). House on the lagoon. New York: Farrar, Strauss \& Giroux.

Ferré. R. (1994). La batalla de las vírgenes. Río Piedras: Editorial Universitaria.

Ferré. R. (1991). On destiny, language, and translation; or, Ophelia Adrift in the C. \& O. Canal. En The Youngest Doll (p. 153165). Lincoln: U of Nebraska Press.

Ferré. R. (1986). Maldito amor. México: Joaquín Mortiz.

Ferré. R. (1976). Papeles de Pandora. México: Joaquín Mortiz.

Ferré. R. (1974). Cuando las mujeres quieren a los hombres. Zona de carga y descarga, 7, (1-7).

García, M. (1988). Historias intimas. Conversaciones con diez escritoras latinoamericanas. Hanover, NH: Ediciones del Norte.

Genette, G. (1997). Paratexts: thresholds of interpretation. Trans. Jane E. Lewin. Cambridge: Cambridge University.

Gentes, E. (2019, $1 .^{\circ}$ de mayo). Updated Bibliography on Self-translation. [Entrada en blog]. En Self-translation. Recuperado de https://self-translation. blogspot.com/2019/05/update-bibliography-on-self-translation.html

Gentzler, E. (2001). Contemporary translation theories. Londres y Nueva York: Routledge.

Giusti, J. A. (1994). De Pandora a Eleguá: una lectura histórica de Rosario Ferré. The House on the Lagoon. Historia y Sociedad, 7, (128-145).

Glissant, E. (1997). Poetics of relation (B. Wing, trad.). Ann Arbor: University of Michigan. DOI: https://doi.org/10.3998/ mpub. 10257

Glissant, E. (1989). Caribbean discourse: Selected essays (J. M. Dash, trad.). Charlottesville: University of Virginia.

Hintz, S. (1995). Rosario Ferré, a search for identity. Nueva York: Peter Lang.
Hokenson, J. W. y Munson, M. (2007). The bilingual text: History and theory of literary self-translation. Manchester: St Jerome.

Irizarry, G. (2001). Travelling Textualities and Phantasmagoric Originals: A Reading of Translation in Three Recent Spanish-Caribbean Narratives. Ciberletras. Revista de crítica literaria y de cultura, 4. Recuperado de http://www.lehman.cuny.edu/ciberletras/v04/Irizarry.html

Jaffe, J. (1995). Translation and Prostitution: Rosario Ferro's Maldito amor and Sweet Diamond Dust. Latin American Literary Review, 23(46), 66-82.

Kumari, P. (2017). Changing paradigms: The role of translation in the colonial and the postcolonial period. Translation Today, 11(2), 156-169.

LePage, R. B. y Tabouret-Keller, A. (1985). Acts of identity: Creole-based approaches to language and ethnicity. Nueva York: Cambridge University Press.

Méndez-Clark, R. (2000). Reescritura, traducción, cambio de voz en Rosario Ferré. $L a$ Torre: Revista de la Universidad de Puerto Rico, 17, 387-417.

Miller, N. (2009). Getting transpersonal: The cost of an academic life. Prose studies: History, theory, criticism, 31(3), 166-180. DOI: https://doi. org/10.1080/01440350903437973

Munday, J. y Meifang Z. (Eds.). (2017). Discourse analysis in translation studies. Amsterdam: John Benjamins Publishing Company. DOI: https://doi.org/10.1075/bct.94

Narayan, R.K. (1979). English in India: some notes on Indian English writing. En M. $\mathrm{K}$. Naik (Ed.), Aspects of Indian writing in English: Essays in honour of professor K. R. Srinivasa Iyengar. Madras: Macmilan.

Naciones Unidas (1960). Resolución de la Asamblea General en la que se definen las tres opciones para alcanzar el gobierno propio. Resolución 1541 (VII). 
Negrón, F. (2016). Sin pelos en la lengua: entrevista a Rosario Ferré. 80grados. Recuperado de http://www.80grados.net/ sin-pelos-en-la-lengua-entrevista-a-rosario-ferre/

Perry, D. (1993). Backtalk: Women Writers Speak Out. New Brunswick: Rutgers University.

Pratt, M. L. (1991). Arts of the Contact Zone. Profession, 91, (33-40).

Rivero, R. (2016, 23 de febrero). Palabras mejor que silencio. El Mundo. Recuperado de https://www.elmundo.es/ cultura/2016/02/23/56cb36af46163f41468b45a5.html

Rosarito Ferré confirma a Avance. (1972, 23 de septiembre). Avance, 5.

Rosarito Ferré... O el otro mundo. (1972, 13 de septiembre). Avance, 5.

Said, E. W. (1993). Culture and imperialism. Nueva York: Knopf.

Salgado, C. (1998). El entierro de González: con (tra) figuraciones del 98 en la narrati- va ochentista puertorriqueña. Revista iberoamericana, 64(184), 413-439.

Santiago, E. (1996). América's dream. Nueva York: Harper Collins.

Sebellin, R. y D'Atena A. (Eds.) (2018). Tradurre se stessi / Translating oneself. Testo e Senso, 19.

Spivak, G. (1988). Can the subaltern speak? En N. Cary y L. Grossberg (Eds.), Marxist interpretations of culture (p. 271-313). Basingstoke: Macmillan Education.

Steiner, G. (1998). After Babel: Aspects of language and translation. Nueva York: Oxford University.

Tolliver, J. (2002). Rosalía between two shores: Gender, rewriting and translation. Hispania, 85(1), 33-43. DOI: https://doi. org/10.2307/4141168

Venuti, L. (1995). The translator's invisibility: $A$ history of translation. Londres y Nueva York: Routledge. DOI: https://doi. org/10.4324/9780203360064

Cómo citar este artículo: Sambolín-Santiago, A. (2019). Las tretas del débil: la autotraducción como subversión lingüística patriarcal en la literatura de la escritora puertorriqueña Rosario Ferré. Mutatis Mutandis. Revista Latinoamericana de Traducción, 12(2), 475-499. DOI: 10.17533/udea. mut.v12n2a07 